\title{
EFL STUDENTS’ PERCEPTION ABOUT MACHINE TRANSLATION
}

\author{
Setia Marito ${ }^{1} \&$ Erwin Ashari $^{2}$ \\ 1,2English Department of Riau Kepulauan University \\ Batam, Indomesia \\ 19 smarito56@gmail.com, ${ }^{2}$ erwinashariharianja83@gmail.com
}

\begin{abstract}
Machine Translation become as alternative to know the meaning of foreign language. Machine Translation was used to translate word, phrase, sentence, pharagraph. text translation was made as a general description and a consederation to get understanding. Machine Transalation can be used as dictionary, too. It is easier to find word by using Machine Translation rather than dictionary. The purpose of using it; to ensure the meaning, to know the meaning and to be more practice. But, Machine Translation leaded them to a confused situation, because sometimes the grammar and structure were different from what they knew and learned, so it made them confused deciding the correct one. Another effect was making them became lazy to open dictionary, to memorize new words.son their problem on using machine translation covers structure/grammar and several words such as idiom.
\end{abstract}

Keywords: Machine Translation, Machine Translation Problems, Structure/Grammar Case.

\section{INTRODUCTION}

Nowadays, it can be seen that many people wherever at public, at school, at society, and even in the business environment use machine translation as the translator. As Hutchins (1986) in Ali (2016) says a machine translation is the software associated with computer systems in the interpretation of text messaging, from one normal language straight into another and Machine Translation is automatic conversion of text/speech from one natural language to another Kunchukuttan (2006). Furthermore Sinhal and Gupta (2014) state Machine translation is a sub-field of computational linguistics that investigates the use of software to translate text or speech from one natural language to another. On a basic level, MT performs simple substitution of words in one natural language for words in another, but that alone usually cannot produce a good translation of a text, because recognition of whole phrases and their closest counterparts in the target language is needed.

Shuttleworth and Cowie (2014) state Machine Translation (MT) or Automatic Translation is a term used to refer to translation which is performed wholly or partly by 
computer. As implied by this definition, such translation may be carried out with or without human intervention; however, if there is a considerable level of intervention, or if computer applications are simply used as "translation tools", then it is more common to talk of Machine-Aided Translation, although the boundary between these two approaches is not always completely clear-cut. Chan (2015) Also says Machine translation (MT) is a sub-field of computational linguistics (CL) or natural language processing (NLP) that investigates the use of software to translate text or speech from one natural language to another. In addition Hutchins (2003) says machine translation (MT) refers to computerized systems responsible for the production of translations with or without human assistance. It means that it can help human on doing translation

According to Sinhal and Gupta (2014) The need for machine translation can be briefly stated into following points briefly: too much to be translated, boring for human translators, major requirement that terminology used consistently, increase speed and throughput, top quality translation not always needed, reduced cost. Absolutely, it is known that machine translation is the easiest and the simple one to translate the other language to the language that human want. The machine translation does not need place and has been known by most of people in the world that use internet. The machine translation can translate word by word or even whole of the text. For example, we can see the picture below:

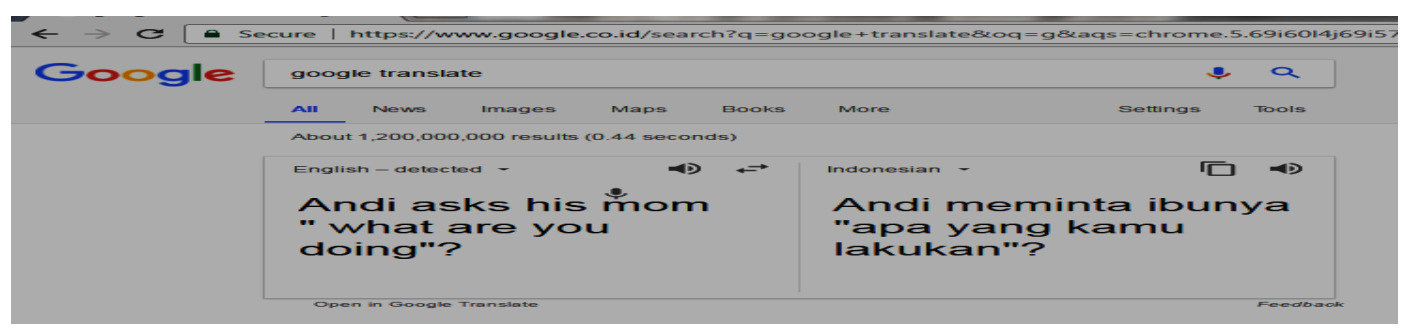

Figure 1. Picture Of English (SL) - Indonesian (TL)Translation By Google Translation

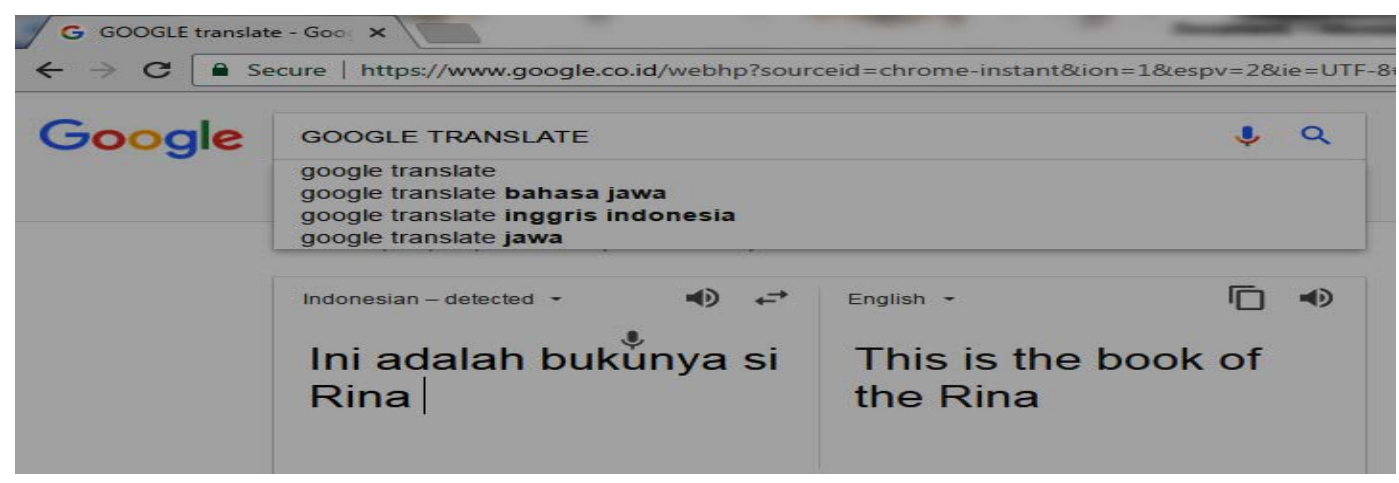

Figure 2. Picture of Indonesian (SL) - English (TL)translation by Google translation 
It is seen that translation from both examples above; those are not as complete as human do. According to Ashari (2015) Meaning is represented by expression or text and expression represents meaning. It means, to express meaning, people use texts or expression. Every text has own meaning that is influenced by the context. So, the correct translation is: 1) Andi bertanya kepada ibunya "Apa yang sedang ibu lakukan”? .So, in machine translation the word " you” was not translated to be "ibu”, meanwhile in the culture of Indonesian in that context you mean "ibu”.In Indonesian context, “you” should be translated into "ibu”. Meanwhile in sentence 2) this is Rina's book. In machine translation does not use apostrophe to show possessive pronoun and article cannot be used before the proper noun such as: name of person and place. Beside it can be found the elliptical clause, and it does not change the perception of the participants understanding (Shalehoddin \& Ashari, 2016), and it cannot be founnd on it.

\section{METHODOLOGY}

Descriptive qualitative method was used in this research. According to Prior (2008) Qualitative methodology is a composite of philosophy, concepts, data-gathering procedures, and statistical methods that provides perhaps the most thoroughly elaborated basis for the systematic examination of human subjectivity. In addition Creswell (2014) says that qualitative methods rely on text and image data, have unique steps in data analysis, and draw on diverse designs.

Keegan (2009) says that qualitative research is less easy to define. It explores questions such as what, why and how, rather than how many or how much; it is primarily concerned with meaning rather than measuring. Although we may refer to the outcomes of qualitative research as data, they are not data in the sense of being facts or statistics. They refer to behavior, thoughts, opinions, meaning and the like. This research was conducted at semseter eight of English Department students of University of Riau Kepulauan. The total number of students as the sample of this study is 25 students who have studied translation subject at sixth semester. And time of the research will hold on August 2017.

Questionnaire used as a tool to gather data or information because a questionnaire is seeking data about service delivery in a nonprofit setting may include space for open-ended 
comments where respondents can indicate why they responded in certain ways or provide details not otherwise captured by closed response items. Prior (2008) Open-ended questionsare often used in qualitative research to explorean issue or concept, to obtain natural wording, to addvariety to a questionnaire, to obtain exact numericaldata, and to provide respondents with opportunitiesfor self-expression or elaboration.

The questionnaires cover 5 indicators that consist 20 items and comments about two translated narrative texts (English- Indonesian and Indonesian -English texts). They are about frequency of machine translation use; the usage of machine translation use; the difficultieson using machine translation;the weakness of machine translation; and the solution on using machine translation.

Creswell (2014) states that the data collection steps include setting the boundaries for the study; collecting information through unstructured or semi structured observations and interviews, documents, and visual materials, as well as establishing the protocol for recording information. So, to collect the data, to all subjects were given shared the questionnaires directly and some questionnaires were sent by email. And then the responses will be analyse as Bodgan 1998 states in Sugiono (2010) data analysis is the process of systematically searching and arranging the interview transcripts, field notes, and other materials that you accumulate to increase your own understanding of them and to enable you to present what you have discovered to others.

\section{FINDING}

Have you ever used machine translation?

Table 1. "Have you ever used machine translation?"

\begin{tabular}{cccc}
\hline No & Answer & Number & Percentage \\
\hline 1 & Yes & 25 & $100 \%$ \\
2 & No & 0 & $0 \%$ \\
\hline & Total & 25 & \\
\hline
\end{tabular}

How often do you use the machine translation?

Table 2. "How often do you use the machine translation?"

\begin{tabular}{clccc}
\hline No & & Answer & Number & Percent \\
\hline 1 & Often & 5 & $20 \%$ \\
2 & Sometimes & 4 & $16 \%$
\end{tabular}




\begin{tabular}{clcc}
3 & three times a week & 1 & $4 \%$ \\
4 & one times a week & 2 & $8 \%$ \\
5 & not really often & 4 & $16 \%$ \\
6 & Rarely & 7 & $28 \%$ \\
7 & every find the difficult and new word & 2 & $8 \%$ \\
\hline \multicolumn{2}{c}{ Total } & 25 & \\
\hline
\end{tabular}

When do you use machine translation (in translating word, sentences or paragraph)?

Table 3. "When do you use machine translation (in translating word, sentences or paragraph)?”

\begin{tabular}{clcc}
\hline No & \multicolumn{1}{c}{ Answer } & Number & Percentage \\
\hline 1 & translate word & 17 & $68 \%$ \\
2 & translate word and sentences & 3 & $12 \%$ \\
3 & When it was needed & 4 & $16 \%$ \\
4 & urgent condition & 1 & $4 \%$ \\
\hline \multicolumn{7}{c}{ Total } & 25 & \\
\hline
\end{tabular}

What type of language do you generally search for in a Machine Translation?

Table 4. "What type of language do you generally search for in a Machine Translation?”

\begin{tabular}{clcc}
\hline No & \multicolumn{1}{c}{ Answer } & Number & Percentage \\
\hline 1 & English & 11 & $44 \%$ \\
2 & English and Indonesian & 7 & $28 \%$ \\
3 & English, Indonesian and French & 1 & $4 \%$ \\
4 & English and Korean & 1 & $4 \%$ \\
5 & English, Japanese, Thai and Korean & 1 & $4 \%$ \\
6 & English and Spanish & 1 & $4 \%$ \\
7 & English and Japanese & 1 & $4 \%$ \\
8 & Germany and Japanese & 1 & $4 \%$ \\
9 & English, Germany, French and Korean & 1 & $4 \%$ \\
\hline & Total & 25 & $100 \%$ \\
\hline
\end{tabular}

Is the language utilized in Machine Translation simple to comprehend?

Table 5. "Is the language utilized in Machine Translation simple to comprehend?” 


\begin{tabular}{|c|c|c|c|}
\hline No & Answer & Number & Percentage \\
\hline 1 & Yes & 10 & $40 \%$ \\
\hline 2 & No & 3 & $12 \%$ \\
\hline 3 & Not really & 2 & $8 \%$ \\
\hline 4 & Seldom & 3 & $12 \%$ \\
\hline \multirow[t]{2}{*}{5} & Sometimes & 7 & $28 \%$ \\
\hline & Total & 25 & \\
\hline
\end{tabular}

Does machine translation translate word by word?

Table 6. “Does machine translation translate word by word?”

\begin{tabular}{|c|c|c|c|}
\hline No & Answer & Number & Percentage \\
\hline 1 & Yes & 19 & $76 \%$ \\
\hline 2 & No & 2 & $8 \%$ \\
\hline 3 & Sometimes & 4 & $16 \%$ \\
\hline & Total & 25 & \\
\hline
\end{tabular}

Does machine translation help you on translation subject?

Table 7. "Does machine translation help you on translation subject?"

\begin{tabular}{clcc}
\hline No & \multicolumn{1}{c}{ Answer } & Number & Percentage \\
\hline 1 & yes & 19 & $76 \%$ \\
2 & Not really & 3 & $12 \%$ \\
3 & Sometimes & 3 & $12 \%$ \\
\hline \multicolumn{2}{l}{ Total } & 25 & \\
\hline
\end{tabular}

What is the role of machine translation for you?

Table 8 "What is the role of machine translation for you?"

\begin{tabular}{|c|c|c|c|c|}
\hline No & Answer & Number & Percentage & \multirow{4}{*}{$\begin{array}{l}\text { How } \\
\text { importance } \\
\text { machine } \\
\text { translation } \\
\text { in your }\end{array}$} \\
\hline 1 & It helps to translate & 16 & $64 \%$ & \\
\hline 2 & it helps to find the new word & 6 & $24 \%$ & \\
\hline 3 & it help if necessary & 3 & $12 \%$ & \\
\hline & Total & 25 & & English \\
\hline
\end{tabular}

Table 9. “How is importance machine translation on your English studies?” 


\begin{tabular}{rrcc}
\hline No & Answer & Number & Percentage \\
\hline 1 & it is very important & 16 & $64 \%$ \\
2 & it is important & 4 & $16 \%$ \\
3 & not really important & 3 & $12 \%$ \\
4 & Sometimes important & 2 & $8 \%$ \\
\hline & Total & 25 & \\
\hline
\end{tabular}

What are the benefits of using machine translation?

Table 10. "what are the benefits of using machine translation?"

\begin{tabular}{clcc}
\hline No & \multicolumn{1}{c}{ Answer } & Number & Percentage \\
\hline 1 & easy and simple to use & 3 & $12 \%$ \\
2 & To shorten time when translate long text & 2 & $8 \%$ \\
3 & it helps at work and study & 3 & $12 \%$ \\
4 & it can help them at work quickly & 4 & $16 \%$ \\
5 & it can be used in urgent condition & 3 & $12 \%$ \\
6 & it can search the new and difficult word fast & 3 & $12 \%$ \\
7 & it can translate word and sentences quickly & 7 & $28 \%$ \\
\hline \multicolumn{4}{c}{ Total } \\
\hline
\end{tabular}

What is the easier one between English- Indonesian and Indonesian -English translation?

Table 11. "What is easier one between English- Indonesian and Indonesian -English translation?”

\begin{tabular}{cccc}
\hline No & Answer & Number & Percentage \\
\hline 1 & English - Indonesian & 11 & $44 \%$ \\
2 & Indonesian - English & 8 & $32 \%$ \\
3 & Both are same & 6 & $24 \%$ \\
\hline & Total & 25 & $100 \%$ \\
\hline
\end{tabular}

What are the effects use Machine translations?

Table 12. "What are the effects use Machine translations?"

\begin{tabular}{|c|c|c|c|}
\hline No & Answer & Number & Percentage \\
\hline
\end{tabular}




\begin{tabular}{|c|c|c|c|}
\hline \multirow{2}{*}{1} & \multicolumn{3}{|l|}{ It help to solve the problem in English Studies } \\
\hline & & 1 & $4 \%$ \\
\hline 2 & $\begin{array}{l}\text { It make us dependence and make us lazy to } \\
\text { open dictionary }\end{array}$ & & \\
\hline & & 11 & $44 \%$ \\
\hline 3 & The result of translation sometimes irrelevant & 2 & $8 \%$ \\
\hline 4 & Could not understand about grammar & 2 & $8 \%$ \\
\hline 5 & $\begin{array}{l}\text { It help to know new word and make sentences } \\
\text { in English }\end{array}$ & 7 & $28 \%$ \\
\hline 6 & $\begin{array}{l}\text { The positive effect it helps to find more words } \\
\text { and negative effect is it decrease our interest to } \\
\text { open dictionary }\end{array}$ & 1 & $4 \%$ \\
\hline 7 & Nothing & 1 & $4 \%$ \\
\hline & Total & 25 & \\
\hline
\end{tabular}

Does Machine translation reduce the interest on learning English?

Table 13. “Does Machine translation reduce the interest on learning English?”

\begin{tabular}{cccc}
\hline No & Answer & Number & Percentage \\
\hline 1 & Yes & 10 & $40 \%$ \\
2 & No & 15 & $60 \%$ \\
\hline & Total & 25 & \\
\hline
\end{tabular}

Can you find all of the words that you are looking for in Machine Translation?

Table 14. “Can you find all of the words that you are looking for in Machine Translation?”

\begin{tabular}{|c|c|c|c|}
\hline No & Answer & Number & Percentage \\
\hline 1 & Yes & 8 & $32 \%$ \\
\hline 2 & No & 12 & $48 \%$ \\
\hline \multirow[t]{2}{*}{3} & Sometimes & 5 & $20 \%$ \\
\hline & Total & 25 & \\
\hline
\end{tabular}

What are the problems that usually faced on using machine translation? 
Table 15 what are the problems that usually faced on using machine translation?

\begin{tabular}{|c|c|c|c|}
\hline No & Answer & Number & Percentage \\
\hline 1 & $\begin{array}{l}\text { sometimes do not have correlation } \\
\text { meaning and incorrect grammar }\end{array}$ & 3 & $12 \%$ \\
\hline 2 & $\begin{array}{l}\text { it is difficult to use if there is no network } \\
\text { sometimes the translation is not }\end{array}$ & 3 & $12 \%$ \\
\hline 3 & appropriate & 14 & $56 \%$ \\
\hline 4 & often find irregular verb & 1 & $4 \%$ \\
\hline 5 & translate word by word & 2 & $8 \%$ \\
\hline 6 & sometimes the result make confused & 1 & $4 \%$ \\
\hline \multirow[t]{2}{*}{7} & there is no problem & 1 & $4 \%$ \\
\hline & Total & 25 & \\
\hline
\end{tabular}

Is the result of translation on using machine translation suitable to the principle of translation?

Table 16 "Is the result of translation on using machine translation suitable to the principle of translation?”

\begin{tabular}{clccc}
\hline No & & Answer & Number & Percentage \\
\hline 1 & Yes & 2 & $8 \%$ \\
2 & No & 14 & $56 \%$ \\
3 & Sometimes & 9 & $36 \%$ \\
\hline \multicolumn{2}{r}{ Total } & 25 & \\
\hline
\end{tabular}

What are your difficulties on using machine translation?

Table 17. "What are your difficulties on using machine translation?

\begin{tabular}{clcc}
\hline No & \multicolumn{1}{c}{ Answer } & Number & Percentage \\
\hline 1 & Need to connect internet & 7 & $28 \%$ \\
2 & $\begin{array}{l}\text { Nothing } \\
\text { sometimes could not found the meaning } \\
3\end{array}$ & 8 & $32 \%$ \\
4 & $\begin{array}{l}\text { of word that want } \\
\text { The grammar is not appropriate }\end{array}$ & 6 & $24 \%$ \\
\hline Total & 25 & $16 \%$ \\
\hline
\end{tabular}


What will you do to solve if you found the different result of machine translation from the principle of translation?

Table 18. what will you do to solve if you found the different result of machine translation from the principle of translation?

\begin{tabular}{clccc}
\hline No & \multicolumn{2}{c}{ Answer } & Number & Percentage \\
\hline \multirow{2}{*}{$\begin{array}{llll}\text { Recheck and rearrange to get a good } \\
\text { translation by their own understanding }\end{array}$} & 15 & $60 \%$ \\
2 & Ask the expert and friends & 5 & $20 \%$ \\
3 & Check it back and find in dictionary & 4 & $16 \%$ \\
4 & No have idea & 1 & $4 \%$ \\
\hline
\end{tabular}

What will you do, after knowing the effect of using Machine translation?

Table 19. What will you do, after knowing the effect of using Machine translation?”

\begin{tabular}{|c|c|c|c|}
\hline No & Answer & Number & Percentage \\
\hline 1 & Still using, when it necessary & 7 & $28 \%$ \\
\hline 2 & Reduce to use machine translation & 8 & $36 \%$ \\
\hline 3 & $\begin{array}{l}\text { Use machine translation just to looking for } \\
\text { the meaning of word }\end{array}$ & 2 & $8 \%$ \\
\hline 4 & $\begin{array}{l}\text { Make sure its result with searching in } \\
\text { dictionary }\end{array}$ & 3 & $12 \%$ \\
\hline 5 & $\begin{array}{l}\text { Study English harder so that do not use it } \\
\text { more }\end{array}$ & 2 & $8 \%$ \\
\hline 6 & Nothing & 2 & $4 \%$ \\
\hline 7 & Often to use it & 1 & $4 \%$ \\
\hline
\end{tabular}

What do you think about machine translation good or bad, why?

Table 20. "What do you think about machine translation good or bad, why?" 


\begin{tabular}{|c|c|c|c|}
\hline No & Answer & Number & Percentage \\
\hline 1 & Good & 5 & $21 \%$ \\
\hline 2 & Bad & 2 & $8 \%$ \\
\hline 3 & Good and Bad & 17 & $68 \%$ \\
\hline & Total & 25 & \\
\hline
\end{tabular}

\section{DISCUSSION}

The results show that all of students has ever used machine. They used Machine Translation for several reasons. They used it for the porpuse; to ensure the meaning, it indicated that they were doubt about their vocabulary masteries. But in onather hand, some of them said that it porpused to know the translation, these students put Machine Translation as a dictionary. But unexpected answer was making it as a tool to make it more practice, these students were students who had no confidenities and efforts to enrich their vocabularies, they just depended on the Machine Translation. This kind of students were not aware of the mistranlation results.

Based on the result, it could be seen that they used Machine Translation to translate, word, phrase, sentence, pharagraph, and even text. It was in dangerous lavel, because it could make them be addicted to the Machine Translation, it was not a good situation for them as students of English Deparment, beside it, it was harmful for them when they had to do direct conversation where there was no time to browse internet.

Most of the studens used Machine Translation more usual on writing and listening rather than reading and speaking needs Their answers were more dominant on searching for English rather than Bahasa Indonesia. Since their daily communication was Bahasa Indonesia and they were seaching English means they focused on writing and listening. If the ficused on reading and speaking needs so, they would searching for Bahasa Indonesia. The word translation that they translated by using machine translation were categorized easy to understand, but it needs more investigation because the researcher was out of control the kind of word they traslated, simple familiar word or unfamiliar words. It becomes as a phenomenon too, because they said that most of the results of machine Translation were tranlated word by word. When it is compared to the theori of translation, it was not the best translation result, because context can chnage the meaning of word. 
Setia Marito \& Erwin Ashari: EFL Students’ Perception About Machine...

Using machine Translation is helpul. Based on the students' answers, its most useful laid on the the practiseness. By using machine translation, they could get a describtion meaning about, words, phrases, sentences, or even pharagraphs faster than opening dictionary. It means that students put Machine Translation as another type of dictionary and as a comparison translation result. They assumed that English - Indonesian is easier translation than Indonesian - English, it an predicted because Bahasa Indonesia is their own language, so that they could predict the meaning based on the sentence context. So, this answer was influenced by the language richness of the users.

Based on the students' answer, the effects of using Machine Translation were three; positive, negatives and no effects. In possitive side, it focused on the practiceness. They can get a general description about word meaning, it just needs context understanding, but Machine Translation leads them to a confused situation, because sometimes the grammar and structure were different from what they knew, so it made them confused deciding the correct one. According to Arnold et al (1994:105-119) state there are three problems used machine translation: Ambiguity, When a word has more than one meaning, it is said to be lexically ambiguous. When a phrase or sentence can have more than one structure it is said to be structurally ambiguous; Lexical and Mismatches, problems arise because different languages use different structures for the same purpose, and the same structure for different purposes. Beside it, they said that Machine Translation made them became more lazy to open dictionary. This dependance made them lazy to memorize new words. And the last was no effect, bu the researcher are doubt about thisanswer, it may be caused by their uncareness about a research. It made two diferent answers that a machine Translation can reduce learning interest; yes and no.

All of the words can be found in machine translation, but it is debatable. Because they were not asked further about kinds of word they were seaching by using Machine Translation. Meanwhile some of them answered yes, it is same as too or they were searching the word not meaning by using key words. It means that it becomes as the next work to make it more detail. Actualy the problems would be faced during Machine Translation, it depends the user to solve it, for example; grammar and structure, type of words and meaning. They can be solve by the user knowledge. So, when the answer was no problem, so it can be predicted that the user were very good or very bad in English. It was good when they could connect the translation text into the context, meanwhile it was very bad because they didi not know the 
corect one, or in another word they had no choice unless accepted it. the funny unswer was because of losing internet connectivity, and it was unacceptable answer. To solve the problems they faced, they consult them to dictionary. Eventhough the sometimes faced some problems or difficulties, they asssumed that Machine Translation was very useful, because it could make their task easier and more practice by having a general meaning of a transaltion text, further they use dictionary co made it more clear.

\section{CONCLUSION}

As the product of technology, Machine Translation become as alternative to know the meaning of foreign language., but not all lanuages are installed in this program, only certain language, generally International and national languages. It becomes as alternative tool for the people. Most of the students in University of Riau Kepulauan at semester eight in 2017 know and use Machin Translation. They use Machine Translation to Translate word, phrase, sentence, pharagraph. They made text translation as a general description and as a consederation to make the real meaning. Beside it, Machine Transalationcan be used as dictionary, too.

Machine Translation is very useful and helpul, it can give a general description to the user, it gives an idea or consedaration to the users to know the meaning. Another side, Machine Translation can be used as a dictionary. It is easier to find word by using Machine Translation rather than dictionary.In machine Translation just by typing but in Dictionary the users must seek alphabetically. Another adventage of Machine Translation is; the user can seek more than one words, eventhough the meaning, strcucture, and grammar but is is useful.

\section{REFERENCES}

Ali, A. (2016). Exploring The Problems Of Machine Translation From Arabic Into Englishlanguage Facedby SaudiUniversity Student Of Translation At The Faculty-- Of Arts,Jazan UniversitySaudi Arabia. IOSR Journal of Humanities and Social Science, 21(4), 55-66. http://doi.org/10.9790/0837-2104025566

Arnold, D., Balkan, L., Humphreys, R. L., Meijer, S., \& Sadler, L. (1994). Machine Translation: An Introductory Guide. Machine Translation. london: NCC Blackwell Ltd.

Ashari, E. (2015). Patterns of Coding in Conversation Texts of the English Zone. Anglo- 
Saxon, 6(8), 39-46.

Chan, S. (2015). The Routledge encyclopedia of translation technology. In S. Chan (Ed.) (first, p. 757). London and New york: Routledge, Taylor and Francis Group. http://doi.org/10.4324/9781315749129.ch3

Creswell, J. W. (2014). Research Design: Qualitative, Quantitative, and Mixed Methods Approaches. Research design Qualitative quantitative and mixed methods approaches. http://doi.org/10.1007/s13398-014-0173-7.2

Gupta, S. and. (2014). Machine Translation Approaches and Design Aspects. Http://www.iosrjournals.org/iosr-Jce, 16(1), 22-25.

Hutchins, J. (2003). Machine Translation: General Overview. The Oxford Handbook of Computational Linguistics.

Keegan, S. (2009). Qualitative Research - Good Decision Making Through Understanding People, Cultures and Markets. (David barr and robin J birn, Ed.), Zhurnal Eksperimental'noi i Teoreticheskoi Fiziki. Lomdon \& Philadelphia: Marker research in practiceseries. http://doi.org/10.2501/S1470785309201247

Prior, L. (2008). Document analysis. ( lisa m Given, Ed.), The Sage Encyclopedia of Qualitative Research Methods (1st \&2nd ed.). london: a sage reference publication. http://doi.org/10.4135/9781412963909

Shalehoddin, \& Ashari, E. (2016). “ MOVE ” ANALYSIS IN CLASSROOM INTERACTION ( An Functional Grammar Approach ). Anglo-Saxon, 7(1), 73-81. Retrieved from http://journal.unrika.ac.id/index.php/jurnalanglo-saxon/article/view/512

Shuttleworth, M., \& Cowie, M. (2014). Dictionary of Translation Studies.

Sugiono. (2010). metode penelitian pendidikan (9th ed.). bandung: alfabeta.

Translation, M. (2006). Machine translation. English. 